\title{
Optimization of culture conditions for in vitro adventitious roots and selected flavonoids production in Boesenbergia rotunda liquid suspension culture
}

\author{
${ }^{1}$ Ghani, K.A., ${ }^{1,2,{ }^{*}}$ Yusuf, N.A. and ${ }^{3}$ Khalid, N. \\ ${ }^{1}$ Faculty of Plantation and Agrotechnology, Faculty of Plantation and Agrotechnology, Universiti Teknologi \\ MARA Cawangan Melaka Kampus Jasin 77300 Merlimau Melaka, MALAYSIA \\ ${ }^{2}$ Agricultural Biotechnology Research Interest Group (RIG), Faculty of Plantation and Agrotechnology, \\ Universiti Teknologi MARA (UiTM) 40450 Shah Alam, Selangor, Malaysia \\ ${ }^{3}$ Centre of Biotechnology for Agriculture Research, Biotechnology and Bioproduct Research Cluster, \\ Institute of Biological Sciences, Faculty of Science, University of Malaya, 50603 Kuala Lumpur, Malaysia
}

\author{
Article history: \\ Received: 23 July 2020 \\ Received in revised form: 10 \\ November 2020 \\ Accepted: 11 December 2020 \\ Available Online: 20 \\ December 2020
}

\section{Keywords:}

Boesenbergia rotunda,

Adventitious roots,

Liquid suspension cultures,

Inoculum density,

$\mathrm{pH}$,

Flavonoids

DOI:

https://doi.org/10.26656/fr.2017.4(S5).018

\begin{abstract}
Boesenbergia rotunda (L.) Mansf. is one of the unique monocotyledonous perennial plant species belonging to the ginger (Zingiberaceae) family. Locally known as 'Temu Kunci' in Malaysia and Indonesia, this medicinal plant has been widely used in Asian dishes, particularly as a condiment or as traditional natural medicines. The important medicinal properties of $B$. rotunda majorly derived from flavonoids which are highly sought as pharmaceuticals. In this study, culture conditions for the growth of adventitious roots in liquid suspension cultures were optimized. The highest adventitious root production was achieved when cultured with initial inoculum density of $1.5 \mathrm{~g}$ and $\mathrm{pH}$ value at 5.8 after five weeks of culture. HPLC analysis discovered that production of valuable flavonoid compounds (pinostrobin, cardamonin and panduratin A) was significantly higher when the adventitious roots were cultured with initial inoculum density of $1.5 \mathrm{~g}$ whereas the initial $\mathrm{pH}$ medium did not significantly affect flavonoid production.
\end{abstract}

\section{Introduction}

Plants are essential to live organisms providing a source of nutrients and oxygen for continuance survival (Usman et al., 2014). Plants that entail with medicinal properties have been the ultimate source of healing for humans for thousands of years. These medicinal plants are used as traditional medicines and serve as the ultimate base for modern drugs and a wide range of natural health products globally (Newman and Cragg, 2012). Around 70 to $80 \%$ of the human population in the developing countries are dependent on medicinal plants as their main health care needs and the numbers keep growing. Hence, the demand for medicinal plants is universally elevated due to the renaissance of interest in herbal medicines-based phytochemicals. This is due to safer option compared to synthetic modern drugs, lower in cost, easy access due to the availability of these plants (Shewamene et al., 2017).

Boesenbergia rotunda is known as fingerroot due to its unique 'finger-like' exterior. This plant is a member of ginger (Zingiberaceae) family that was believed to be native to China, India and Southeast Asia regions including Sri Lanka, Thailand, Malaysia and Indonesia.
Owing to its distinctive aroma, this monocotyledonous herb often used as a condiment in various Asian cooking particularly to promote appetite. It is also the famous ingredient in old folk remedies such as in preparing women special tonic called 'Jamu'. The rhizome of this herb plant has been traditionally used to treat abdominal pain or gastric caused by gas. In addition, it helps to reduce swelling, healing fresh cuts and often used as homegrown hair lotion to prevent hair loss (Tan et al., 2011).

The medicinal properties of $B$. rotunda are mainly derived from its flavonoids, the most plentiful secondary metabolites found in this plant species. Rhizome of $B$. rotunda plant consists of three main groups of flavonoids; flavanones, flavones and chalcones. These compounds are reported to be important for pharmacological applications (Chahyadi et al., 2014). Three flavonoids from the in vitro adventitious roots of $B$. rotunda had been evaluated in this present study, which are pinostrobin, cardamonin and panduratin A. Pinostrobin is classified as flavones while cardamonin and panduratin A are chalcones (Kirana et al., 2007). Pinostrobin is a major bioactive compound found in $B$. 
rotunda plant and reported to exhibit anti-leukaemia activity (Sukari et al., 2007), elevated activity of an antioxidant enzyme and quinine reductase, and possessed anti-aromatase activity (Le Bail et al., 2000; Fahey and Stephenson, 2002). This flavone compound is also proven as potential bioactive compound against breast cancer MDA-MB-231 cell/line and colon cancer HT-29 cell line (Mohammed et al., 2019). As for cardamonin, this compound had previously been reported to exhibit anti-cancer activity (Mohammed et al., 2019) and antiHIV activity (Tewtrakul et al., 2003). Meanwhile, Panduratin A and 4-hydroxypanduratin A in the rhizome of $B$. rotunda were known to display high inhibition towards dengue- 2 virus protease (Kiat et al., 2006).

Secondary metabolites of plants naturally accumulate in particular tissues and structures including specialized glands, vacuoles, trichomes and more. The production of these compounds is highly influenced by plant physiology, genotype, weather, surroundings and pathogens. In some circumstances, they can only be synthesized at certain developmental phases (Isah et al., 2018).

In recent years, plant tissue culture techniques involving manipulation of a plant cell, tissue and organ cultures had been widely used as a modern alternative to attain highly valuable secondary metabolites from plants. These in vitro techniques are used as motives to limit the usage of space and time at the highest rate of propagation (Cardoso et al., 2019). Amongst all in vitro culture techniques, organ culture specifically adventitious root culture has been the most eye-catching. It is acknowledged as an efficient in vitro system to produce higher biomass in a short period along with stable productivity of important secondary metabolites in plants (Wang et al., 2013). These techniques are considered to be simple as it requires minimal culturing steps and easy transfer procedures. Therefore, it is comparatively easy to control any physical and chemical changes with adventitious root cultures. Due to these advantages, the up-scaling process of adventitious roots cultures into larger reactor vessels (bioreactors) will also be an easy task (Baque et al., 2012). As compared to other culture techniques which include cell, embryo and intact plants, adventitious root culture has been extensively used due to constant production of bioactive compounds which are competent and have closest resemblances with those attained from the mother plants (Murthy and Paek, 2016)

This present work aimed to investigate the effect of culture conditions for in vitro adventitious root cultures of $B$. rotunda in liquid shake flask system, as well as enhancing selected flavonoids through the establishment of initial inoculum density and $\mathrm{pH}$ medium. To the researcher's best knowledge, there have been no investigation reported on optimizing culture conditions for adventitious root in liquid suspension cultures for this particular species.

\section{Materials and methods}

\subsection{Plant material and culture conditions}

Well established in vitro adventitious roots, cultured in liquid medium of half basal Murashige and Skoog (1962) supplemented with $0.5 \mathrm{mg} / \mathrm{L}$ 1-Naphthaleneacetic acid (NAA) (Azhar et al., 2018) were used as initial plant materials. This same liquid culture medium of $1 / 2$ MS medium supplemented with $0.5 \mathrm{mg} / \mathrm{L}$ NAA was used as a treatment medium in this study. The $\mathrm{pH}$ of culture medium was set beforehand at $\mathrm{pH} 5.8$ by adding $1.0 \mathrm{M}$ sodium hydroxide $(\mathrm{NaOH})$ or $1.0 \mathrm{M}$ hydrochloric acid $(\mathrm{HCl})$ prior to autoclaving at $121^{\circ} \mathrm{C}(105 \mathrm{kPa})$ for 18 mins. The medium was added with $3 \%(w / v)$ sucrose as the carbon source. Root weight of $1.0 \mathrm{~g}$ was inoculated into $250 \mathrm{~mL}$ conical flask containing $50 \mathrm{~mL}$ of treatment medium for subsequent experiments. All treatment cultures were agitated on an orbital shaker at the speed of $100 \mathrm{rpm}$ in $24 \mathrm{hrs}$ darkness at $25 \pm 2^{\circ} \mathrm{C}$. Each experiment was repeated three times in six replications. The adventitious root growth and the production of selected flavonoids of $B$. rotunda in vitro were evaluated by the root biomasses. The growth data were presented in the form of mean fresh weight (FW) and dry weight (DW). The adventitious roots were harvested from each treatment and fresh weight was recorded at the end of $5^{\text {th }}$ week of culture. The dry weight was obtained by ovendried the adventitious roots at $38^{\circ} \mathrm{C}$ for $72 \mathrm{hrs}$ or until a constant weight was achieved.

2.2 Culture conditions affecting the growth and production of the adventitious roots of selected flavonoids of Boesenbergia rotunda

\subsubsection{Effects of Initial inoculum density}

The effects of the initial inoculum density were observed at different weights of initial inoculum (0.5, 1.0, 1.5, 2.0 and $2.5 \mathrm{~g}$ ) (Yusuf et al., 2013; Haida et al., 2019). The final weight of adventitious roots harvested was recorded to determine the increment in adventitious root biomass after five weeks of culture.

\subsubsection{Effect of medium $\mathrm{pH}$}

The effects of initial $\mathrm{pH}$ values were examined within the range of 4.8 to 6.8 . The $\mathrm{pH}$ of the medium tested was adjusted to $4.8,5.8$, and 6.8 by adding $0.1 \mathrm{~N}$ $\mathrm{NaOH}$ or $0.1 \mathrm{~N} \mathrm{HCl}$. pH 5.8 was used as a control in this experiment. 


\subsection{Quantification of selected flavonoids contents from using SPSS.} adventitious root cultures

\subsubsection{Extraction of flavonoids from in vitro adventitious roots}

The harvested in vitro adventitious roots were thoroughly washed with distilled water and oven-dried at $38^{\circ} \mathrm{C}$ for $48 \mathrm{hrs}$ until the constant dry weight was achieved. The dried roots were then pounded into powder form using mortar and pestle. Powdered samples weighed $0.1 \mathrm{~g}$ were soaked into $10 \mathrm{~mL}$ methanol $72 \mathrm{hrs}$. After 72 hrs, the mixture was filtered through a No. 1 Whatman filter paper. The filtrates were concentrated using a rotary evaporator of (BÜCHI Rotavapor R-114). The slurry residue was then partitioned against an equal volume of ethyl acetate and distilled water. Ethyl acetate fraction part was again evaporated. The mass of the partitioned ethyl acetate extract was recorded and redissolved in methanol at a ratio of $1.0 \mathrm{mg}$ of extract to $0.2 \mathrm{~mL}$ methanol. This methanolic solution of the extract was filtered through a $0.45 \mu \mathrm{m}$ PTFE filter (Sartorius 13 CR) prior to HPLC injection (Yusuf et al., 2013).

\subsubsection{HPLC analysis}

HPLC analysis was done via Agilent 1100 Series HPLC system which comprised of G1310A isocratic pump with solvent cabinet, G1328A automatic injector (AI), G1314A variable wavelength detector (VWD) with standard flow cell $(10 \mathrm{~mm}$ path length, $14 \mu \mathrm{L}$ volume, 40 bar maximum pressure) and G2220AA 2D-Value Solution ChemStation. The reverse column Chromolith RP-18e, (100 x $4.6 \mathrm{~mm}$ i.d.; $2 \mu \mathrm{m})$ (Merck) provided with guard cartridges RP-18e ( 5 x 4.6 mm i.d.; Merck) was used. The injection volume was adjusted to $20 \mu \mathrm{L}$ per injection with a total run time of 18 minutes with a flow rate of $1.5 \mathrm{~mL} / \mathrm{min}$. The selected flavonoid compounds were observed at a wavelength of $285 \mathrm{~nm}$ to $330 \mathrm{~nm}$. The gradient solvent systems used for elution were a mixture of $0.1 \%$ phosphoric acid (A) (R\&M Chemicals) and HPLC grade acetonitrile (B), Merck brand. These gradient solvents started at $0 \mathrm{~min}$ with $100 \%$ acetonitrile. Then followed by $80 \%$ phosphoric acid and $20 \%$ acetonitrile for $0.5 \mathrm{~min}, 65 \% \mathrm{~A}$ and $35 \% \mathrm{~B}$ at $4.5 \mathrm{~min}, 40 \% \mathrm{~A}$ and $60 \% \mathrm{~B}$ at $5.0 \mathrm{~min}$ and final 8.0 min with $100 \% \mathrm{~B}$. The selected flavonoid compounds of pinostrobin, cardamonin and panduratin A were detected and quantified by matching their retention times and spectral characteristics with known standards that had been attained and recognized formerly.

\subsection{Experimental design and statistical analysis}

All data from each parameter were analysed using One-Way ANOVA followed by mean comparison tested using Duncan's Multiple range test (MRT) at $p \leq 0.05$

\section{Results and discussion}

3.1. Effect of culture conditions on adventitious root growth and selected flavonoids

\subsubsection{Effect of initial inoculum density}

Production of important plant secondary metabolites from the in vitro adventitious roots is highly dependent on the initial inoculum density and differs by the plant species (Gonçalves and Romano, 2018). The initial inoculum density is one of the most crucial factors that determine cell growth in plant tissue culture. It involves the interaction of cells to cells and cells to the medium. Failure of growth in cell or organ cultures are often caused by the use of a critically minimum amount of inoculum weight (Aly et al., 2010). Therefore, it is crucial to determine suitable initial inoculum density to ensure optimum growth of adventitious root biomass together with the secondary metabolites production in vitro.

In the present study, mean increased of fresh weight (FW) produced from all initial inoculum tested $(0.5,1.0$, $1.5,2.0,2.5 \mathrm{~g})$ were $(0.44 \pm 0.09,0.45 \pm 0.11,1.78 \pm 0.27$, $0.64 \pm 0.14$ and $0.99 \pm 0.29 \mathrm{~g}$ ) and dry weights (DW) obtained were $(0.07 \pm 0.00, \quad 0.11 \pm 0.01, \quad 0.25 \pm 0.01$, $0.17 \pm 0.01,0.21 \pm 0.02 \mathrm{~g}$ ) (Figure 1). Based on these results, the in vitro adventitious roots of $B$. rotunda in liquid suspension cultures displayed a cumulative trend of root biomasses both in mean fresh weight (FW) and dry weight (DW) as the initial inoculum density increased up to intermediate level and started to decline when initial inoculum density increased to $2.0 \mathrm{~g}$ and above. Low initial inoculum density, $0.5 \mathrm{~g}$ resulted in low biomasses production (Figure 1). This occurred due to critical small mass, which is inadequate for cells survival, plus abundant nutrients amount in the liquid media caused adversative effects on cell growth. The initial inoculum density of $1.5 \mathrm{~g}$ was found to produce the highest biomasses with significant mean increased in final root biomasses of $1.78 \pm 0.27 \mathrm{~g}(\mathrm{FW})$ and $0.25 \pm 0.01$ g (DW) respectively. Meanwhile, adventitious root biomasses started to show significant decrement when the initial inoculum density was further increased to 2.0 $\mathrm{g}$ and $2.5 \mathrm{~g}$ (Figure 1). This happened because higher inoculum densities caused high competition among root cells during nutrients and oxygen uptake. The lack of nutrients and oxygen suppressed the growth of root cells and decreased the root biomass production. The results obtained were related to morphological observations presented in Figure 2.

In terms of selected flavonoids production, the highest accumulation of pinostrobin, cardamonin and 
panduratin A were also achieved in the initial inoculum density of $1.5 \mathrm{~g}$. The adventitious roots harvested from the initial inoculum density of $1.5 \mathrm{~g}$ produced significantly higher contents of pinostrobin, cardamonin and panduratin A with $0.20 \pm 0.08 \mathrm{mg} / \mathrm{g}, 0.41 \pm 0.00 \mathrm{mg} / \mathrm{g}$ and $0.08 \pm 0.01 \mathrm{mg} / \mathrm{g}$ respectively compared to the other initial inoculum densities tested. The production of cardamonin and panduratin was least favoured when cultured in initial inoculum density of $2.5 \mathrm{~g}$ with only $0.03 \pm 0.01$ and $0.01 \pm 0.00 \mathrm{mg} / \mathrm{g}$ respectively (Figure 3).

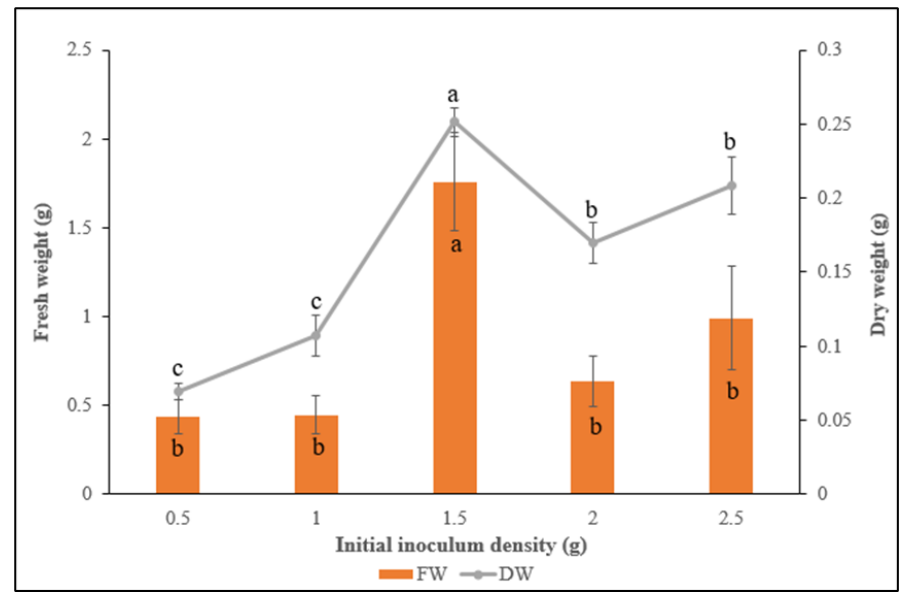

Figure 1. Effects of initial inoculum density on adventitious root biomass production in liquid suspension cultures of $B$. rotunda after five weeks of culture. Values with different alphabets for each parameter are significantly different via Duncan's multiple range (DMRT) test $(\mathrm{p} \leq 0.05)$.
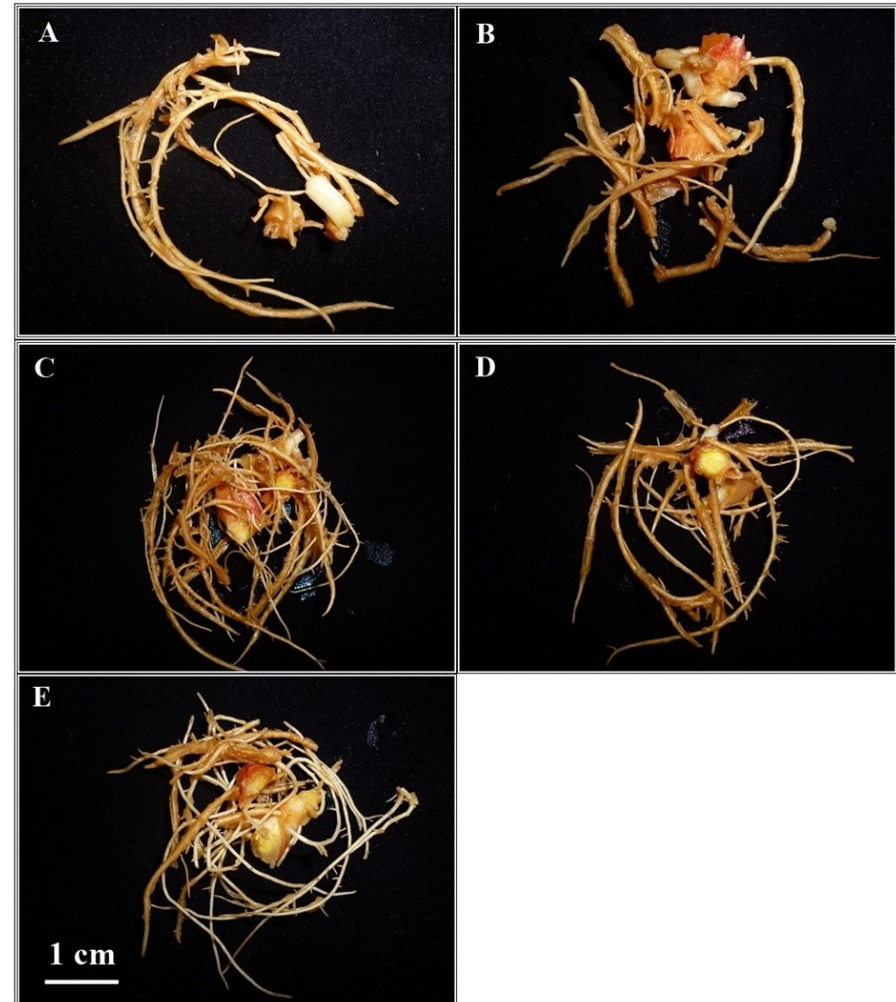

Figure 2. In vitro adventitious roots of $B$. rotunda harvested from different initial inoculum densities after five weeks of culture (A) 0.5 g. (B) 1.0 g. (C) 1.5 g. (D) 2.0 g. (E) 2.5 g, $\mathrm{n}=6$

These results were in agreement with the previous study on cell suspension of $B$. rotunda done by Yusuf et al. (2013). They reported among all inoculants tested $(0.25,0.50,1.00$ and $1.50 \mathrm{~mL}$ of SCV), the application of intermediate inoculant of $2 \%(1 \mathrm{~mL}$ of SCV: $50 \mathrm{~mL}$ media) significantly produced higher biomass and flavonoid compounds with $0.25 \pm 0.04 \mathrm{~g}$ mean DW and $15.11 \pm 4.83 \mu \mathrm{g} / \mathrm{g}$ respectively. Higher inoculant of $3 \%$ (1.5 mL SCV: $50 \mathrm{~mL}$ media) showed a significant decline in final biomass and the cells started to turn brown within 12 days of culture. However, this treatment did not affect the flavonoid production.

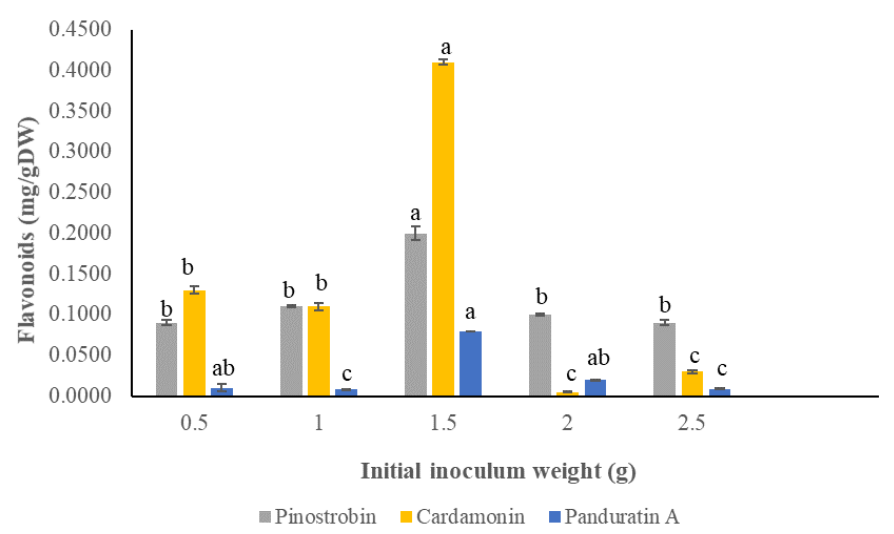

Figure 3. Effects of different initial inoculum density on selected flavonoids from adventitious roots of $B$. rotunda after five weeks. Values with different alphabets are significantly different via Duncan's multiple range (DMRT) test $(\mathrm{p} \leq 0.05)$.

The outcomes of this study might show dissimilarity from previous studies due to factors of different plant species and different culture system used (Lee and Shuler, 2000). Nonetheless, a similar pattern of root biomass production was also reported by Raju et al. (2015) on adventitious root cultures of Curcuma amada Roxb. (mango ginger) This study had tested initial inoculum density in the range of $2.5 \mathrm{~g}$ up to $20.0 \mathrm{~g}$. Among these inoculums, the intermediate weight of $10 \mathrm{~g}$ was found to be the best initial inoculum density as it produced maximum adventitious root biomass for mango ginger after five weeks of culture. The overall outcomes in this study also presented that further decrease or increase in inoculum density led to a drop in the root biomass production of curcuma amada Roxb.

The optimum growth and secondary metabolites production in vitro adventitious roots frequently achieved at certain initial inoculum density. Commonly, higher initial inoculum density in a range of $2.0 \mathrm{~g}$ to 5.0 $\mathrm{g}$ showed poor development of adventitious roots. This happened due to higher rivalry between root cells as they are cramped together at high densities and affect nutrients uptake process which resulted in lesser cells proliferation (Amoyel and Bach, 2014). A similar effect was also observed in an attempt of upscaling adventitious roots of Hypericum perforatum in a bioreactor. The adventitious roots of Hypericum 
perforatum showed increased of final weight root biomass as the initial inoculum density increased but tremendously declined in growth ratio. Lower inoculum density, less than $6 \mathrm{~g} / \mathrm{L}$ produced lower root biomass. In opposite, the root biomass increased with both inoculum densities of $8 \mathrm{~g} / \mathrm{L}$ and $10 \mathrm{~g} / \mathrm{L}$ but displayed a reduction in growth ratio with only $31.8 \%$ and $44 \%$ respectively (Cui et al., 2010).

A study by Ho et al. (2017) demonstrated the effect of initial inoculum density on adventitious root cultures of Polygonum multiflorum. This study had proved that 7 $\mathrm{g} / \mathrm{L}$ was the preferred initial inoculum density to obtain maximum root biomass between all inoculum densities ( $3 \mathrm{~g} / \mathrm{L}$ to $15 \mathrm{~g} / \mathrm{L}$ ) tested. Conversely, lower initial inoculum, $5 \mathrm{~g} / \mathrm{L}$ was found ideal to produce significantly higher flavonoids and phenolic compounds with 53.87 $\mathrm{mg} / \mathrm{g}$ DW and $27.96 \mathrm{mg} / \mathrm{g}$ DW respectively. A recent study by Haida et al. (2019) revealed that highest cells biomass of $F$. deltoidea var. kunstleri was obtained when cultured with initial inoculum density of $2.0 \mathrm{~g}$ and required only $0.5 \mathrm{~g}$ to produce highest flavonoid content of $3.3 \mathrm{mg} \mathrm{RE} / \mathrm{g}$ DW. This study also reported declining in flavonoid contents as the initial inoculum density increased, $1.0 \mathrm{~g}$ to $2.0 \mathrm{~g}$ with only $2.9 \mathrm{mg} \mathrm{RE} / \mathrm{g} \mathrm{DW}$ and $2.7 \mathrm{mg} \mathrm{RE} / \mathrm{g} \mathrm{DW}$, respectively.

Based on results obtained in Figure 1 and Figure 3, it is proven that the initial inoculum density did give effect on the adventitious root growth and production of flavonoid compounds in the adventitious root of $B$. rotunda. The intermediate inoculum density of $1.5 \mathrm{~g}$ is the most ideal for adventitious root in liquid suspension cultures for $B$. rotunda species. It can also be concluded that initial inoculum weight is a crucial factor to determine success or failure of plant tissue. Too low of initial inoculum density caused incapability to survive while too high of initial inoculum leads to suppression of cell growth and lessen the accumulation of secondary metabolites.

\subsubsection{Effect of $p H$}

The success in achieving optimum growth and development of plant cell, tissue and organ cultures are highly determined by the establishment of hydrogen and ion concentration $(\mathrm{pH})$. An ideal initial $\mathrm{pH}$ value is crucial as it regulates the biological reactions in organs, tissues or cells including nutrient uptake, enzymatic processes and hormonal activities. Generally, the $\mathrm{pH}$ value will be attuned at 5 to $6 \mathrm{pH}$ prior to autoclaving. This range of $\mathrm{pH}$ values is considered reliable in avoiding extreme $\mathrm{pH}$. This step is crucial to prevent $\mathrm{pH}$ fluctuations during culture and to reach the stability of $\mathrm{pH}$ medium before the explants been inoculated (Rao and Ravishankar, 2002).
In this present study, the adventitious root growth of $B$. rotunda had been significantly affected by the initial $\mathrm{pH}$ values $(4.8,5.8$ and 6.8) tested. After five weeks of culture, the adventitious roots harvested from initial $\mathrm{pH}$ treatment of 5.8 was found to be significantly higher in mean FW $(2.08 \pm 0.001 \mathrm{~g})$ and DW $(0.15 \pm 0.007 \mathrm{~g})$ (Figure 4). Meanwhile, the adventitious roots obtained from the initial $\mathrm{pH}$ treatments of 4.8 and 6.8 were not significantly different towards one another in term of mean fresh weight $(1.72 \pm 0.007 \mathrm{~g}$ and $1.61 \pm 0.001 \mathrm{~g})$ and dry weights of $0.13 \pm 0.001 \mathrm{~g}$ and $0.11 \pm 0.001 \mathrm{~g}$, respectively. Figure 5 displayed the morphological observations of in vitro adventitious roots harvested from all initial $\mathrm{pH}$ treatments.

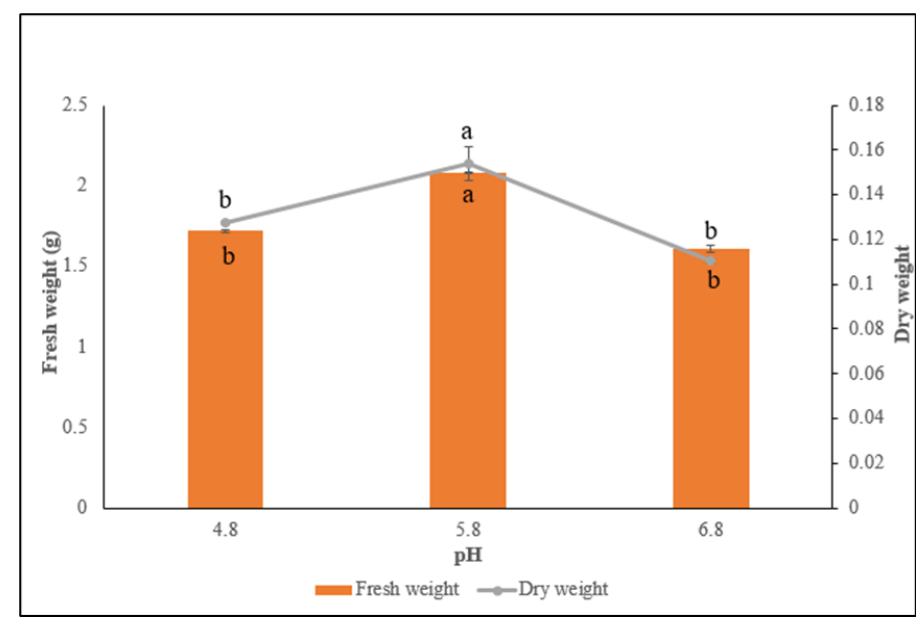

Figure 4. Effects of $\mathrm{pH}$ medium on adventitious root biomass production in liquid suspension cultures of $B$. rotunda after five weeks of culture. Values with different alphabets for each parameter are significantly different via Duncan's multiple range (DMRT) test $(\mathrm{p} \leq 0.05)$.
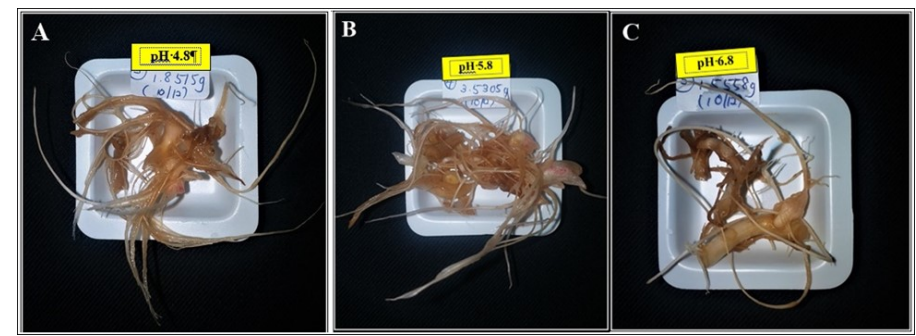

Figure 5. In vitro adventitious roots harvested from different $\mathrm{pH}$ treatments after five weeks of culture. (A) $\mathrm{pH} 4.8$, (B) $\mathrm{pH}$ 5.8 and $(\mathrm{C}) \mathrm{pH} 6.8, \mathrm{n}=6$

A comparable study was done by Jalil et al. (2015) on cell suspension cultures of Zingiber zerumbet Smith reported that the highest growth rate of 0.0707 was achieved in medium $\mathrm{pH}$ 5.7. Decreased of cells proliferation was assessed in media with an initial $\mathrm{pH}$ of 5.7 to 6.2. Meanwhile, production of zerumbone was found higher $(4.00 \pm 0.26 \mathrm{mg} / \mathrm{L})$ in media of initial $\mathrm{pH}$ 5.2 .

Similar outcomes attained by Murthy and Praveen (2013), demonstrated that optimum production of adventitious roots biomass (113.26 g/L FW and $11.33 \mathrm{~g} /$ 
L DW) of Withania somnifera (L.) Dunal were achieved in medium of initial pH 5.8. However, the withanolide A production was highest $(9.09 \mathrm{mg} / \mathrm{g}) \mathrm{DW})$ in the initial medium $\mathrm{pH}$ 5.5. In addition, the same trend also was presented by Radić (2016) for shoot culture of Stevia rebaudiana (Bert). This study had stated that the shoot height was significantly taller when cultured in a medium with an initial $\mathrm{pH}$ of 5.8 and $\mathrm{pH}$ 7.4. However, the best metabolites production of the Stevia leaf was obtained in the $\mathrm{pH}$ treatment of 4.6 .

Optimum growth of cells in in vitro is influenced by initial $\mathrm{pH}$ of the medium. Low $\mathrm{pH}$ (acidic) conditions boosted the hydrolysis process which allows energy to be supplied much faster. The presence of acid enhanced hydrolysis procedure by efficiently breakdowns the glycosidic bond in sucrose to provide instantaneous energy for the root cells. Higher energy helps the root cells to grow vigorously thus increases the root biomass. In contrast, higher initial $\mathrm{pH}$ values (alkaline conditions) slow down the hydrolysis process which then caused inadequate energy supply to the cells. The deficiency of energy during culture disrupted the growth of cells thus decreases the root biomass (Hedrich et al., 1989; Felle, 2001).

Contradictory to the root biomass production, the selected flavonoid (pinostrobin, cardamonin and panduratin A) contents were not significantly affected by all pH treatments. Based on Figure 6, the accumulation of pinostrobin was significantly higher in both media of initial $\mathrm{pH}$ of 5.8 and 6.8 with $0.43 \pm 0.005$ and $0.43 \pm 0.003$ $\mathrm{mg} / \mathrm{g}$ respectively. Meanwhile, cultures treated with the initial $\mathrm{pH}$ of $\mathrm{pH} 4.8$ significantly enhanced cardamonin production $(0.31 \pm 0.003 \mathrm{mg} / \mathrm{g} \mathrm{DW})$ compared to $\mathrm{pH} 5.8$ $(0.25 \pm 0.167 \mathrm{mg} / \mathrm{g})$. In contrast, a lower content of cardamonin $(0.06 \pm 0.003 \mathrm{mg} / \mathrm{g} \mathrm{DW})$ was observed in media at $\mathrm{pH}$ 6.8. Panduratin $\mathrm{A}$ accumulation was significantly higher in both initial media $\mathrm{pH}$ of 4.8 and 5.8 with the amount of $0.20 \pm 0.002 \mathrm{mg} / \mathrm{g}$ and $0.21 \pm 0.010$ $\mathrm{mg} / \mathrm{g}$ compared to initial $\mathrm{pH} 6.8$ with only $0.08 \pm 0.006$ $\mathrm{mg} / \mathrm{g}$. In plant tissue culture, it is crucial for the basal medium to be adjusted slightly acidic prior to autoclaving and is necessary for transduction process. Acidic basal medium function to imitate acidification in cytoplasm, stimulating gene transcription of phenylalanine ammonia lyase, involves in phenylpropanoid pathway which synthesizes flavonoids (Rao and Ravishankar, 2002; Haida et al., 2019).

Initial $\mathrm{pH}$ of the medium in plant tissue culture is vital to ensure successful growth and development of cell, tissues or organs in in vitro. $\mathrm{pH}$ could affect membrane penetrability, the respiratory metabolism, polyamine metabolism, protein synthesis, and the hormones activities and indirectly affected the growth and development of culture materials (Ding et al., 2008). Respond and acceptance to changes of $\mathrm{pH}$ during in vitro culture regularly differ according to the requirements of one plant species (Chen et al., 2014). The results obtained from this study showed that the production selected flavonoids of $B$. rotunda were differently affected by the initial $\mathrm{pH}$ medium. The selected flavonoids (pinostrobin, cardamonin and panduratin A) production seems to prefer lower $\mathrm{pH}$ medium of 4.8 and 5.8. Initial $\mathrm{pH}$ medium of 5.8 was suggested to be the most ideal for the adventitious root of $B$. rotunda species as it successfully enhanced root biomass and flavonoids production.

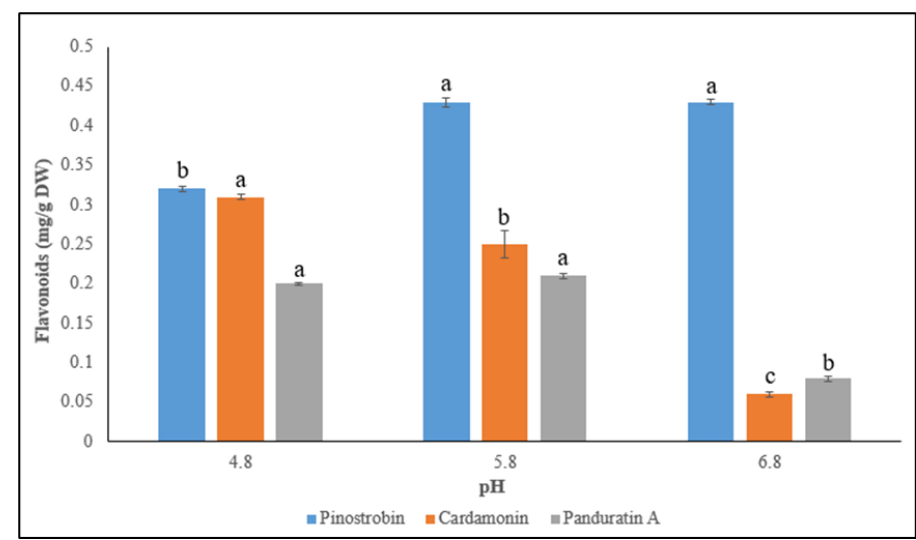

Figure 6. Effects of different initial $\mathrm{pH}$ on selected flavonoids from adventitious roots of $B$. rotunda after five weeks. Values with different alphabets for each parameter are significantly different via Duncan's multiple range (DMRT) test $(\mathrm{p} \leq 0.05)$.

\section{Conclusion}

The adventitious root biomass and accumulation of selected flavonoids; pinostrobin, cardamonin and panduratin $\mathrm{A}$ of $B$. rotunda via liquid suspension system were successfully enhanced when cultured with $1.5 \mathrm{~g}$ of initial inoculum density and initial medium $\mathrm{pH}$ of 5.8. These fruitful outcomes have unlocked the possibilities of other culture conditions (MS salt strength, carbon source, temperature and photoperiod) to be explored, ensuring maximum production of biomass and secondary metabolites. In addition, elicitation and precursor feeding strategies also could be applied to enhance the flavonoids production up to the same level or higher from the intact plants. The repercussion of this present work could be useful for a larger scale of in vitro cultivation via bioreactor vessels in obtaining continuous supplies of these valuable bioactive compounds in the future.

\section{Conflict of interest}

The authors declare no conflict of interest in this present study. 


\section{Acknowledgements}

We thanked Universiti Teknologi MARA (UiTM) for financially supporting this study through a research grant No.600-IRMI/GIP (015/2019).

\section{References}

Aly, U.I., Shabrawi, H.M.E. and Hanafy, M. (2010). Impact of culture conditions on alkaloid production from undifferentiated cell suspension cultures of Egyptian Henbane. Australian Journal of Basic and Applied Sciences, 4(10), 4717-4725.

Amoyel, M., Simons, B.D. and Bach, E.A. (2014). Neutral competition of stem cells is skewed by proliferative changes downstream of $\mathrm{Hh}$ and Hpo. EMBO Journal, 33(20), 2295-2313. https:// doi.org/10.15252/embj.201387500

Azhar, S.Z.A., Ghani, K.A. and Yusuf, N.A. (2018). In vitro induction of adventitious root from shoot bud of Boesenbergia rotunda (Zingiberaceae): Effect of plant growth regulators. Science International (Lahore), 30(1), 147-151.

Baque, M. A., Elgirban, A., Lee, E.J. and Paek, K.Y. (2012). Sucrose regulated enhanced induction of anthraquinone, phenolics, flavonoids biosynthesis and activities of antioxidant enzymes in adventitious root suspension cultures of Morinda citrifolia (L.). Acta Physiologiae Plantarum, 34, 405-415. https:// doi.org/10.1007/s11738-011-0837-2

Cardoso, J.C., Oliviera, M.E.B.S. and Cardoso, F.C.I. (2019). Advances and challenges on the in vitro production of secondary metabolites from medicinal plants. Horticultura Brasileira, 37, 124-132. https:// doi.org/10.1590/s0102-053620190201

Chahyadi, A., Hartati, R., Wirasutisna, K.R. and Elfahmi. (2014). Boesenbergia pandurata Roxb. an Indonesian medicinal plant: Phytochemistry, biological activity, plant biotechnology. Procedia Chemistry, 13, 13-37. https://doi.org/10.1016/ j.proche.2014.12.003

Chen, C.C., Bates, R. and Carlson, J. (2014). Effect of environmental and cultural conditions on medium $\mathrm{pH}$ and explant growth performance of Douglas-fir (Pseudotsuga menziesii) shoot cultures, F1000 Research, 3, 298. https://doi.org/10.12688/ f1000research.5919.2

Cui, X.H., Chakrabaty, D., Lee, U.J. and Paek, K.Y. (2010). Production of adventitious roots and secondary metabolites by Hypericum perforatum L. in a bioreactor. Bioresource Technology, 101(12), 4708-4716. j.biortech.2010.01.115

Fahey, J.W. and Stephenson, K.K. (2002). Pinostrobin from honey and Thai ginger (Boesenbergia pandurata): A potent flavonoid inducer of mammalian phase 2 chemoprotective and antioxidant enzymes. Journal of Agricultural and Food Chemistry, 50, 7472-7476. https://doi.org/10.1021/ jf025692k

Felle, H.H. (2001). pH: signal and messenger in plant cells. Plant Biology, 3, 577-591. https:// doi.org/10.1055/s-2001-19372

Gonçalves, S. and Romano, A. (2018). Production of plant secondary metabolites by using biotechnological tools. In Vijayakumar, R. (Ed.) Secondary Metabolites: Sources and Applications. Intechopen E-Book. https://doi.org/10.5772/ intechopen.76414

Hedrich, R., Kurkdjian, A., Guern, J. and Flügge, U. (1989). Comparative studies on the electrical properties of the $\mathrm{H}^{+}$translocating ATPase and pyrophosphatase of the vacuolar-lysosomal compartment. The EMBO Journal, 8(10), 2835. https://doi.org/10.1002/j.1460-2075.1989.tb08430.x

Ho, T., Lee, K. and Lee, J. (2017). Adventitious root culture of Polygonum multiflorum for phenolic compounds and its pilot-scale production in $500 \mathrm{~L}$ tank. Plant Cell Tissue and Organ Culture, 130, 167 -181. https://doi.org/10.1007/s11240-017-1212-9

Isah, T., Umar, S., Mujib, A., Sharma, M.P., Rajasekharan, P.E., Zafar, N. and Frukh, A. (2018). Secondary metabolism of pharmaceuticals in the plant in vitro cultures: Strategies, approaches, and limitations to achieving higher yield. Plant Cell Tissue and Organ Culture, 132, 239-265. https:// doi.org/10.1007/s11240-017-1332-2

Jalil, M., Annuar, M.S., Tan, B.C. and Khalid, N. (2015). Effects of Selected Physicochemical Parameters on Zerumbone Production of Zingiber zerumbet Smith Cell Suspension Culture. Evidence-based Complementary and Alternative Medicine, 7, 757514. https://doi.org/10.1155/2015/757514

Kiat, T.S., Pippen, R., Yusof, R., Ibrahim, H., Khalid, N. and Rahman, N.A. (2006). Inhibitory activity of cyclohexenyl chalcone derivatives and flavonoids of fingerroot, Boesenbergia rotunda (L.), towards dengue-2 virus NS3 protease. Bioorganic and Medicinal Chemistry Letters, 16(12), 3337-3340. https://doi.org/10.1016/j.bmcl.2005.12.075

Kirana, C., Jones, G., Record, I. and McIntosh, G. (2007) Anticancer properties of panduratin A isolated from Boesenbergia pandurata (Zingiberaceae). Journal of Natural Medicines, 61, 131-137. https:// doi.org/10.1007/s11418-006-0100-0

Le Bail, J.C., Aubourg, L. and Habrioux, G. (2000). 
Effects of pinostrobin on estrogen metabolism and estrogen receptor transactivation, Cancer Letters, 156(1), 37-44. https://doi.org/10.1016/S0304-3835 (00)00435-3

Mohammed, I., Akhtar, M., Biau, F., Tor, Y.S., Zareen, S., Shahabudin, S., Hamid, H., Ul-Haq, Z., Khalil, R. and Khalaf, R. (2019). Isolation of cardamonin, pinostrobin chalcone from the rhizomes of Boesenbergia rotunda (L.) Mansf. and their cytotoxic effects on H-29 and MDA-MB-231 cancer cell lines. The Natural Products Journal, 9(4), 341348. https:// doi.org/10.2174/2210315509666190117151542

Murashige, T. and Skoog, F. (1962). A revised medium for rapid growth and bioassays with tobacco tissue cultures. Physiologia plantarum, 15(3), 473-497. https://doi.org/10.1111/j.1399-3054.1962.tb08052.x

Murthy, H.N. and Paek, K.Y. (2016). Panax ginseng adventitious root suspension culture: Protocol for biomass production and analysis of ginsenosides by high pressure liquid chromatography. In: Jain, S.M. (Ed.). Protocols for In Vitro Cultures and Secondary Metabolite Analysis of Aromatic and Medicinal Plants, 2nd ed., p. 125-139. New York: Springer. https://doi.org/10.1007/978-1-4939-3332-7_9

Murthy, H.N. and Praveen, N. (2013). Carbon sources and medium $\mathrm{pH}$ affects the growth of Withania somnifera (L.) Dunal adventitious roots and withanolide A production. Journal of Natural Products Research, 27(2), 185-189. https:// doi.org/10.1080/14786419.2012.660691

Murthy, H.N., Kee, J.H. and Paek, K.Y. (2008). Adventitious roots and secondary metabolism. Chinese Journal of Biotechnology, 24(5), 711-716. https://doi.org/10.1016/S1872-2075(08)60035-7

Newman, D.J. and Cragg, G.M. (2012) Natural Products as Sources of New Drugs over the 30 Years from 1981 to 2010. Journal of Natural Products, 75, 311335. https://doi.org/10.1021/np200906s

Radić, S. (2016). Influence of $\mathrm{pH}$ and plant growth regulators on secondary metabolite production and antioxidant activity of Stevia rebaudiana (Bert). Periodicum Biologorum, 118, 9-19. https:// doi.org/10.18054/pb.2016.118.1.3420

Raju, S.R., Varutharaju, K., Thilip, C., Aslam, A. and Shajahan, A. (2015) Rhizogenesis in cell suspension culture from Mango Ginger: A Source of Isosorbide and n-Hexadecanoic Acid. Advances in Botany, 2015, 942761. https://doi.org/10.1155/2015/942761

Shewamene, Z., Dune, T. and Smith, C. A. (2017). The use of traditional medicine in maternity care among African women in Africa and the diaspora: a systematic review. BMC Complementary and Alternative Medicine, 17, 382. https:// doi.org/10.1186/s12906-017-1886-x

Sukari, M.A., Lian, G.E.C. and Khalid, K. (2007). Cytotoxic constituents from Boesenbergia pandurata (roxb.) schltr. Natural Product Sciences, 13(2), 110113

Tan, E.C., Lee, K.Y., Chee, C.F., Heh, C.H, Wong, S.M., Christina Thio, L.P., Foo, G.T., Norzulani, K., Norsaadah, A.R., Saiful Anuar, K., Shatrah, O., Rozana, O. and Rohana, Y. (2012). Boesenbergia rotunda: From Ethnomedicine to Drug Discovery. Hindawi Publishing Corporation, 2012, 473637. https://doi.org/10.1155/2012/473637

Tewtrakul, S., Subhadhirasakul, S., Puripattanavong, J. and Panphadung, T. (2003). HIV-1 protease inhibitory substances from the rhizomes of Boesenbergia pandurata, Holtt. Songklanakarin Journal of Science and Technology, 25(4), 503-508.

Usman, A.B., Abubakar, S., Alaku, C. and Nnadi, O. (2014). Plant: a Necessity of Life. International Letters of Natural Sciences, 20, 151-159. https:// doi.org/10.18052/www.scipress.com/ILNS.20.151

Wang, J., Man, S., Gao, W., Zhang, L. and Huang, L. (2013). Cluster analysis of ginseng tissue cultures, dynamic change of growth, total saponins, specific oxygen uptake rate in bioreactor and immunoregulative effect of ginseng adventitious root. Industrial Crops and Products, 41, 57-63. https:// doi.org/10.1016/j.indcrop.2012.04.005

Yusuf, N.A., Annuar, M.S.M. and Khalid, N. (2013). Physical stress for overproduction of biomass and flavonoids in cell suspension cultures of Boesenbergia rotunda, Acta Physiologiae Plantarum, 35, 1713-1719. https://doi.org/10.1007/ s11738-012-1178-5 